\title{
An analysis of insurance claim cost-ratios in the professional civil liability of specialist physicians in Gynaecology-Obstetrics in Switzerland from 2008- 2017: a retrospective study
}

\author{
M P Mathey ${ }^{1}$, Me I Jaques ${ }^{2}$, R Barras ${ }^{3}$, R Bäntsch ${ }^{4}$ and A Feki*1 \\ ${ }^{1}$ Gynecology and Obstetrics Department, Hospital Cantonal, 6 chemin des pensionnats, Fribourg 1708, Switzerland
} ${ }^{2}$ Attorney, SBA specialist Barrister in Liability and insurance law, Avocats Leman, Av du Léman 30 Lausanne ${ }^{3}$ lic. iur, ARM, Head Litigation Romandie \& Ticino at Zurich Insurance Company Ltd ${ }^{4}$ Senior Underwritter Liability at Zurich Insurance Company Ltd

*Corresponding author: A Feki, Gynaecology and Obstetrics Department, Hôpital Cantonal, 6 chemin des pensionnats, Fribourg 1708, Switzerland

\section{ARTICLE INFO}

Received: 岿 July 11, 2019

Published: 蔧 July 23, 2019

Citation: M P Mathey, Me I Jaques, R Barras, R Bäntsch, A Feki. An analysis of insurance claim cost-ratios in the professional civil liability of specialist physicians in Gynaecology-Obstetrics in Switzerland from 2008-2017: a retrospective study. Biomed J Sci \& Tech Res 19(5)-2019. BJSTR. MS.ID.003370.

Keywords: professional civil liability; Gynaecology Obstetrics; claim; private and public practice

Abbreviations: PC: Penal Code, CO: Code of Obligations, HospP: Hospital Practice, PrP: Private Practice

\begin{abstract}
Background: Interest for medical liability or malpractice is growing. In the United States, $74 \%$ of specialist physicians in gynaecology-obstetrics are subject to a malpractice claim at least once during their career. Medical civil liability is incurred when the practitioner who caused the damage is answerable to the law and must compensate the financial loss and moral damage caused, through the payment of consequential damages to the injured party. The quantity of cases announced to assurance companies can represent the "insurance claim cost-ratio", a possible instrument for medical practice and improvement. After a reminder of the Swiss legal framework, we sought to quantify the number of cases reported to Zurich Insurance Company Ltd (a Swiss insurance company) that systematically gathered data concerning disputes between patients and doctors (or hospitals) for whom it provides cover for civil and professional liability. We evaluate the different financial compensation amount especially those concerning Gynaecology Obstetrics and the judiciary proceeding results.
\end{abstract}

Results: This is a retrospective, non-randomized study with anonymous data. From 2008 through September 2017, 5'173 incidents in medical civil liability were announced; 4'448 concerned hospital practice and 725 were from private practice. Representing 9.1\% of all claims reported, gynaecology obstetrics is placed in second position of the classification of specialties according to the number of cases (469 cases). Only 3\% of the claims made under civil liability medical insurance (for all branches) results in judiciary proceedings. The majority of claims in gynaecology-obstetrics are settled with financial compensations inferior to CHF 50,000 but the average sum per case is more than twice as high than the other specialities.

Conclusion: Gynaecology obstetrics belongs to a medical branch that is strongly affected by insurance claim. Because of this important number of cases and high financial compensation amount, precautionary measures should be taken. Keeping a complete medical file, maintaining dialogue with the patient in case of disputes, or offering ongoing training in order to prepare medical teams to face the risks are suggestions to improve the medical outcomes and lower the number of claims. 


\section{Introduction}

Medical liability is an issue that has steadily grown in interest over recent years [1]. In the United States, studies have shown that $74 \%$ of specialist physicians in gynaecology-obstetrics are subject to a malpractice claim at least once during their career [2]. No matter their mode of medical practice (private physician or in public/private hospital), the apprehension caused by the prospect of formal complaints inevitably leads medical practitioners to modify the care they give to their patient groups, with repercussions from financial, administrative and human perspectives.

\section{Legal Framework}

The term "insurance claim cost-ratio" (sinistralité)-the theme of this article-is borrowed from the vocabulary of insurance. It designates the quantity of cases announced to an insurance company following the claim of an injured party. The financial ratio derived from this number can represent an instrument for the improvement of medical practice. The liability of a Swiss medical practitioner can be civil, criminal or administrative. Civil liability occurs when the practitioner who caused the damage is answerable to the law and must compensate the financial loss and moral damage caused through the payment of consequential damages to the injured party. This can be done either through a civil or criminal court trial, or in an extra-judicial manner through an amicable settlement between the parties. Criminal liability is incurred when there has been a violation of a criminal norm. Following a criminal offence according to article 1 Penal Code (PC) (p.e. negligent homicide - art. 117 PC, bodily injury caused by negligence - art. 125 PC, breach of patient confidentiality - art 321 PC etc.), the resulting sentence imposed by the state through a legal proceeding can range from a fine to a custodial sentence.

Administrative liability [3] is based on the breach of a professional rule contained within administrative laws or within the ethical rules of the profession. This can lead to administrative penalties or the withdrawal of the right to practice medicine. Regardless of the way the claim is made; civil or criminal trial or a compromise procedure, it is the issue of civil liability that will be covered here. In Switzerland, the relationship that links a medical practitioner to his or her patient is either governed by private practice (general practice or private medicine within a private hospital) or the public hospital system. The liability of a doctor employed by a public hospital is governed by public law, which is usually cantonal. In such cases it is the state that acts as the intermediary between the two parties because the patient and the doctor are not connected by a legal bond. In a second phase, the state can turn against the doctor to obtain redress. Within a private establishment, a private or independent medical practitioner enters into a care contract with his or her patient which is governed by the rules of a mandate contract pursuant to Art. 394 ss Code of Obligation (CO).

It is important to note that, even if the legal norms that deal with civil liability differ, the conditions that give rise to it overlap.
Whether liability is examined from the standpoint of contractual, tortious or public law, it must first be determined if a doctor has violated the rules of their profession and/or if they have neglected to obtain the free and informed consent of their patient; both of which are conditions that incur civil liability.

The doctor is bound by an obligation of means and not of results. In other words, the physician is obliged to provide care in the broadest sense of the term, but he/she is not obliged to guarantee the recovery of the patient. Their main obligation is to provide the services they have promised within the terms of the contract or pursuant to the standards of the profession for the good and faithful execution of the mandate. Failure to respect this obligation corresponds to infringing one's duty of diligence, which in turn overlaps with the notion of the violation of professional rules [4] set by the present and generally accepted standards and principles established by medical science.

The "Tribunal Fédéral" (Swiss federal court) has estimated that proof of the existence and violation of professional rules must be borne by the patient. If they fail to provide such evidence, the doctor's liability cannot be incurred. On the other hand, doctors are required to inform their patients of the possible risks incurred through their care (except in cases of vital emergency or loss of the capacity of discernment) to allow them to exercise their free will and therefore give their informed consent. Proof of full disclosure devolves to the doctor and has become very important in the physician-patient relationship, creating an active partnership in a care contract. For a doctor's liability to be incurred, a natural and adequate causal relationship must be established between the damage and the conduct giving rise to the liability and the said loss. The calculation for the compensation is subject to a strict framework and is defined as the reimbursement of the costs and the payment to cover a damage-award or the moral wrongs suffered by the patient as a result of the damage.

\section{Medical Framework}

Even though a change in mentality at the level of the profession has facilitated the recognition of medical errors, the subject remains taboo [5]. A systematic census of the number of accidents or of criminal/civil proceedings does not exist in Switzerland. In France, MACFS-the first insurance company in medical civil liability-reported a rise in claims of $8.7 \%$ in one year in its annual 2016 report, placing the medical specialisation of gynaecologyobstetrics in 6th position and in 3rd position of specialities with the highest compensation costs. The report also brings to light a hardening of the judicial process, with more convictions at the civil level than in the year 2015, increasing from 59\% to 66\%. Gynaecology-obstetrics is a constantly evolving medical and surgical field dedicated to the health of women. These physicians monitor pregnancies, childbirth, pathologies related to the female genitalia, as well as correlated surgical procedures. From a medical standpoint, this discipline is not without risks of complications, ranging from the death of patients to the loss of the unborn child. 
Strictly speaking, obstetric risks have risen due to the demographic evolution of maternal characteristics, even if maternal mortality has been continuously decreasing, affecting 5/100,000 births in Switzerland in 2015 according to IndexMundi (data portal). The rise in the complexity of risk-prone care is notably correlated with a number of factors: higher maternal age at the moment of birth [6,7], morbidity and chronic pathologies of parturient women; there are also at-risk pregnancies due to medically-assisted procreation, which has led to riskier pregnancies [8]. This speciality is known to be highly litigious in different countries such as The United States [9]. Zurich Insurance Company Ltd is a Swiss insurance company founded in 1872. It has systematically gathered data concerning disputes between patients and doctors (or hospitals) for whom it provides cover for civil and professional liability. The insurance company has agreed to share access to its data. As it covers over one third of the Swiss market in medical third-party liability insurance coverage (doctors and

\section{Results}

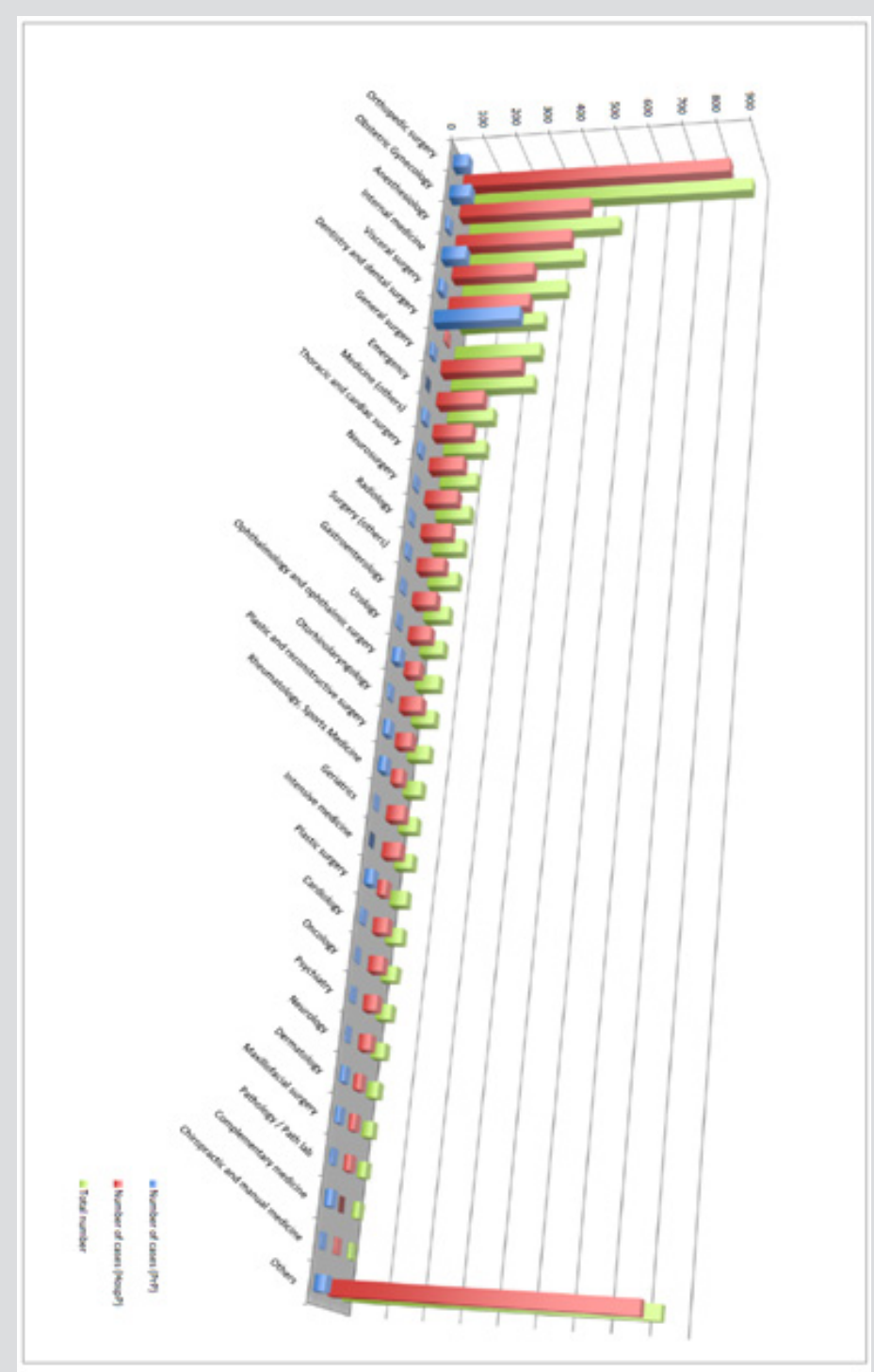

Figure 1: Distribution of the number of claims from 2008 to September 2017 according to medical discipline and to the nature of the care, hospital or private.

establishments), this represents a large enough sample to enable a relevant analysis of the current situation.

\section{Goals}

The goals of this study are to quantify the number of cases reported to Zurich Insurance between 2008 and September 2017 and extract those that concern gynaecology-obstetrics practitioners exclusively, distinguish between the data gathered in private practice and hospital practice (private and public), evaluate a median cost per case, describe the average time needed to resolve a claim, assess the proportion of accidents subject to an extrajudicial settlement or jurisdictional procedure and-amongst these-those that are subject to an ongoing transaction procedure and those that have resulted in a court decision.

\section{Method}

This is a retrospective, non-randomized study with anonymous data derived from Zurich Insurance Company Ltd. 
The number of incidents in medical civil liability announced from 2008 to September 2017 amounts to 5173; 4448 cases concern hospital practice (hereinafter HospP) and 725 cases are from private practice (hereinafter PrP), for a total cost exceeding CHF 114 million (PrP: CHF 13.4 mio; HospP: CHF 101.5 mio). We notice that amongst all the announced PrP cases, the medical specializations that are most concerned by insurance claim costs are dentistry (35.57\%), general medicine (10.34\%), obstetricsgynaecology $(9.1 \%)$, orthopaedic surgery $(6.62 \%)$, plastic surgery and ophthalmology (3.31\%) (cf) (Figure 1). The remaining 41.68\% are spread out amongst the remaining specialisations. Amongst HospP, orthopaedic specialisation holds the top spot (18.4\%), followed by obstetrics-gynaecology (9.1\%), internal medicine (5.6\%), visceral surgery (5.6\%) and general surgery (5.51\%). The remaining balance is distributed between the different specialities at the rate of a few percent points each. The higher number of claims in hospital practice affects the global distribution between the two sectors.

469 cases for gynaecology-obstetrics occurred during that period (HospP 403, PrP: 66). The discipline of gynaecologyobstetrics represents $9.1 \%$ of all claims reported, placing it in second position, behind the orthopaedic specialisation. In private practice, we notice more cases related to gynaecology $(6.48 \%$ of the total) than obstetrics ( $2.62 \%$ of the total), with a generally similar share between the two sub-practices in public practice $4.9 \%$ in gynaecology, $4.16 \%$ obstetrics). Underlying the claims in obstetric gynaecology, the causes that are most often noted are mistakes during surgical care (about 50\%), errors in diagnostics, errors in nursing care, or mistakes in drug prescription. In more than $70 \%$ of the cases, documentation and information protocols were duly filled out (Figure 1). The color green represents the total number of cases. The color red represents cases in hospital care (HospP). The blue color represents the number of cases in private care (PrP). In the event of amicable settlements, the percentage of cases filed without financial compensation is globally the same between PrP and HospP: at the rate of one out of two (HospP: 54.3\%; PrP: $44 \%$ ). This distribution is comparable to other specialities (HospP: 55.7\%; PrP: 45.1\%).

Overall, we observe that only $3 \%$ of the claims made under civil liability medical insurance (for all branches) resulted in judiciary proceedings. This is however an indication and not a statistic because precise data is not available. On the total number of cases identified during the given period (2008-2017), most (more than $85 \%$ ) were settled by a judiciary transaction or by the doctor's exoneration (Figure 2). The total cost of claims related to gynaecology-obstetrics amounts to CHF 20.27 million, which represents $17.6 \%$ of the total claims amount. Once again, orthopaedics comes out on top with $23.6 \%$ of the total sum. The majority of claims in gynaecology-obstetrics are settled with compensations inferior to CHF 50,000 (HospP: 78.8\%; PrP: 83.7\%) (cf) (Figure 3). Despite the large number of "modest claims", the total sum for these indemnities only represents $18.7 \%$ of the total amount in PrP and $11.8 \%$ in HospP. The weight of claims for important amounts therefore represents a non-negligible part of the total amount at a rate of $65.3 \%$ for 5 cases (2.7\% of the total number) in HospP and $41.3 \%$ for a single case in PrP.

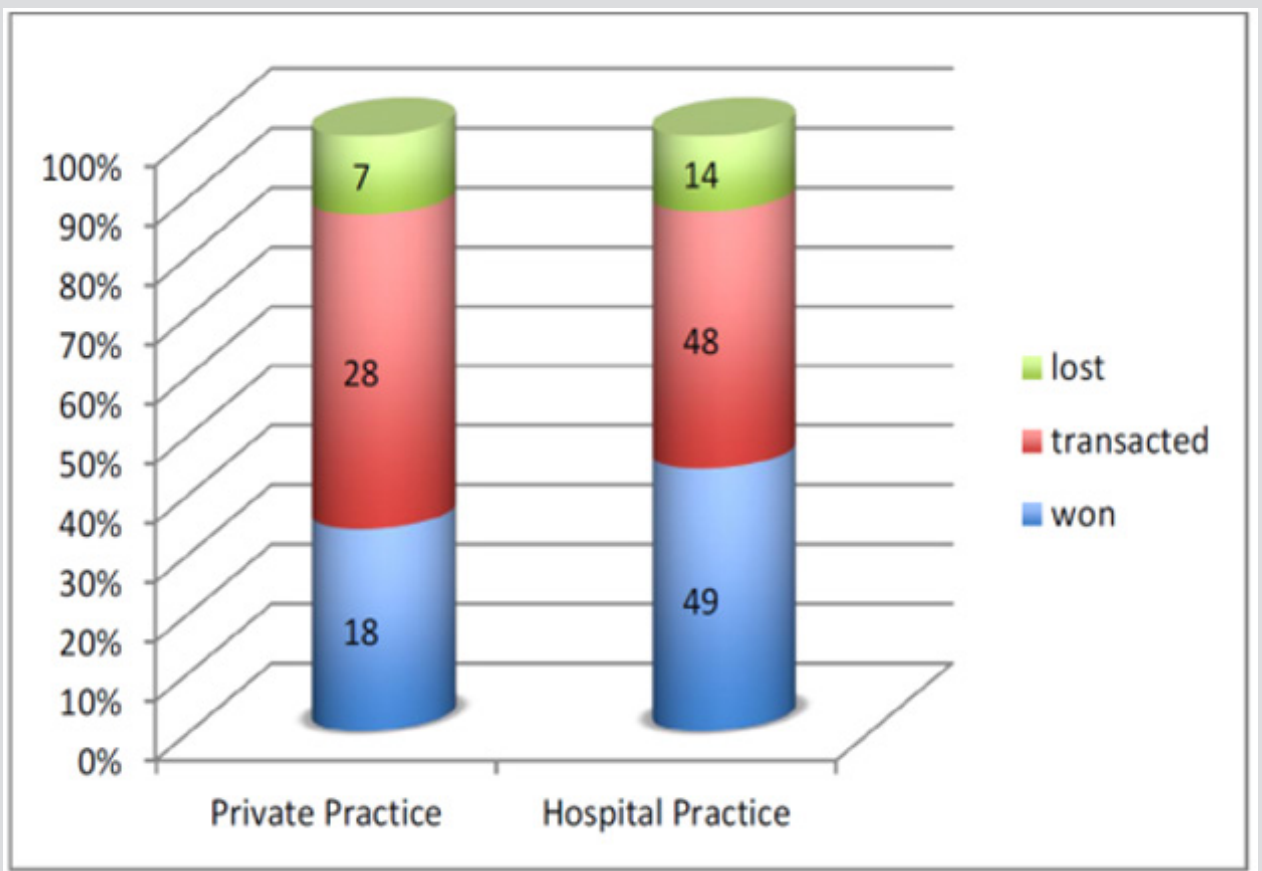

Figure 2: Resolution of cases in civil procedure between 2008 and September 2018, as it relates to private and hospital care. Number of total cases: 164 for all specializations. 


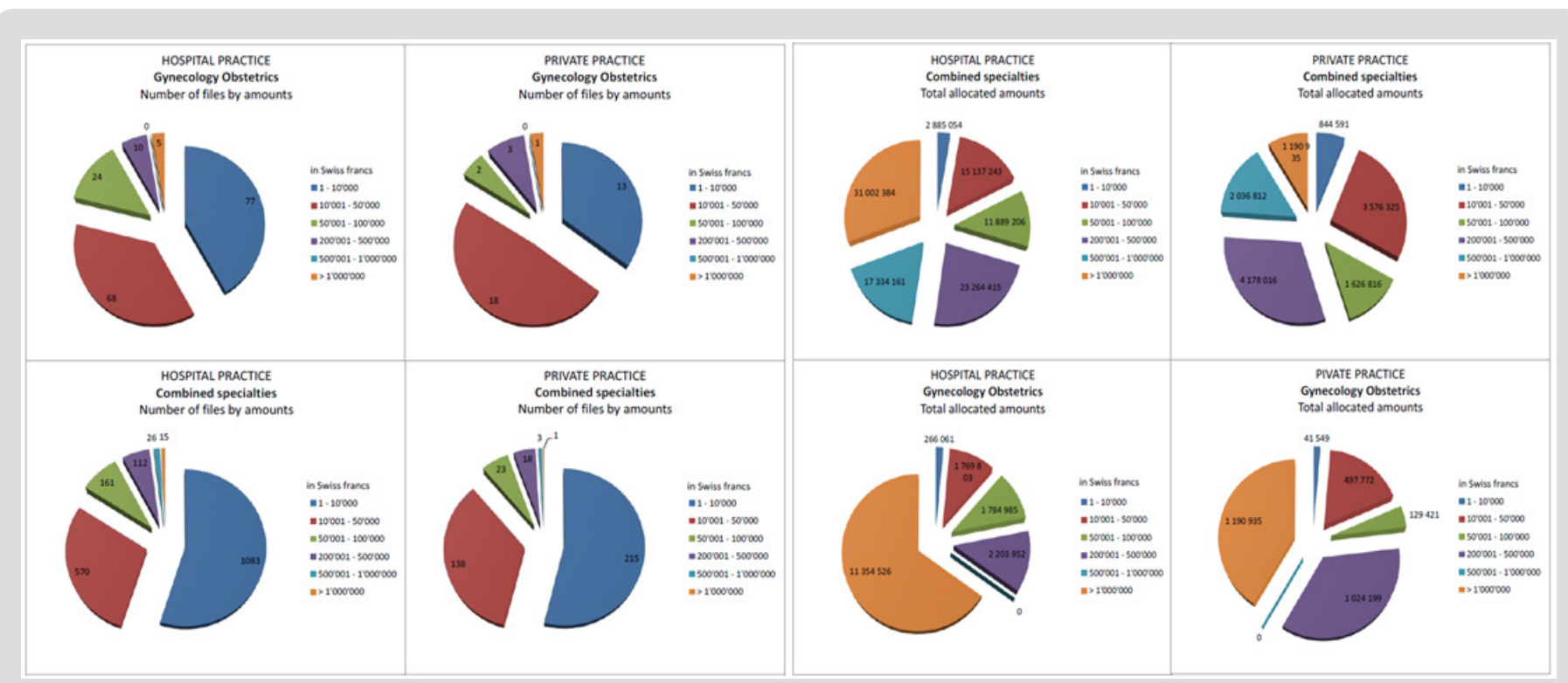

Figure 3: Distribution of financial compensation in private or hospital practice per portion amount or proportional usage of the total sum.

The distribution by amounts for the other specialities is more homogenous, with most cases being settled for amounts less than 10,000 CHF. The average sum per case (evaluated through the median) amounts to CHF 16,097 for a case in HospP and CHF 27,374 for a case in PrP, which is twice as high as in other specialities (HospP: CHF 7,587; PrP: CHF 10,000) (Figure 3). A majority of cases are resolved with a compensation amount less than CHF 50,000 . For all combined specialties as well as in the public practice of gynaecology, the majority of compensations are for amounts inferior to CHF 10,000. In private practice, a majority of claims are compensated with amounts ranging from CHF 10,000 to CHF 50,000 . Compensations for "large amounts" contribute heavily to the total budget amount in gynaecology-obstetrics. It constitutes the largest share of the budget in the public or private branch and is far more significant than in other specialties.

\section{Discussion}

Switzerland has no institutional body for the observation of medical risks. Many French institutions exist, such as "l'Office National d'Indemnisation des Accidents Médicaux (ONIAM)", a public establishment tasked with the administrative procedures for the amicable compensation of victims of medical accidents. The number of registered claims is therefore known on a national level. Due to the absence of a medical, state or insurance supervisory body in Switzerland, it is difficult to find meaningful and reliable data on this subject. In our study, we can see that in Switzerland, gynaecology-obstetrics is a medical branch that is heavily affected by claims. There is a globally homogenous distribution of the number of cases between the two sub-specialities. A claim made within this speciality is more onerous than in other specialities, with an average amount per case that is twice as great as in other specialities. This observation is shared by ONIAM and even the Sham (a French in- surance company specialised in the insurance of risk management for hospitals. This company owns a majority share of the said market and insures close to $2 / 3$ of the births in France).

Even though a majority of the cases observed in our study were settled amicably or with compensations lower than CHF 50,000, certain cases can lead to financial compensations upward of 1 million Swiss francs. This has significant consequences on the distribution of future compensation budgets (provisions). However, our study doesn't allow us to conclude that there is a rise in insurance claims in Switzerland. France, on the other hand, has brought to light a rise in the number of claims over the past few years within all medical specialities. The origin of this phenomenon is very likely multifactorial. The mentality of patients has evolved over time to reach the status of care partner today. This has destroyed the paternalistic and intimidating status of doctors, whose knowledge was previously undisputed. As patients become more involved in their treatment and care [10], it is understandable that they should express their discontent when they are not satisfied [11]. The evolution of technology - along with a certain hyper-specialisation of care-can lead to the false impression that the total efficiency of medical knowledge has suppressed the risk that is inherent to medical practice, which is considered a thing of the past.

A high level of technicity and expertise can obscure an important aspect of the contract which provides an obligation of means, but not of results; patients now tend to think that successful treatment is guaranteed. Despite some very important scientific and technological advances, this reasoning is obviously wrong since risk is an integral part of any medical activity. According to a report by the Sham, $80 \%$ of claims in obstetrics occur during birth. The improvement of obstetric care, correlated with the increased medicalization of childbirth, has allowed for a decrease 
in maternal and infant morbidity. This can lead to the belief that life-threatening risks have completely disappeared. However, even in physiological conditions, pregnancy and childbirth involve a vital risk that persists to this day. A retrospective study by a French university hospital studying the subject of claims between 1997 and 2010 brought to light that $34 \%$ of claims were related to the late or non-implementation of Caesarean sections. This suggests that many perceive this technique as a miracle solution which can limit neonatal or maternal morbidity/mortality.

This in turn implies a rise in the rate of the surgical operation without necessarily lowering the rate of cerebral palsy [12]. The periparturient period is unusual in that it can cause injury to the mother and have heavy repercussions-notably neurologicalon the life of the child. In obstetrics, the medical act directly involves two patients. This is a feature specific to this speciality. A complicated childbirth can therefore lead to two casualties. The father and other members of the family can also be aggrieved. Owing to an increase in the number of different actors involved, we must also note that the nature of the relation between doctors and patients has also evolved, making care more anonymous. Indeed, it is rare for a single gynaecologist to be responsible for monitoring the entire pregnancy and perform the delivery, as was customary in the past. It is interesting to note that the majority of claims made to Zurich Insurance Company Ltd relate to the sub-branch of gynaecology and not obstetrics, and more specifically to surgical care. It seems important to highlight that the specialities that are most affected by insurance claims (orthopaedics, gynaecology, anaesthesiology, vascular surgery etc.) all involve a procedure that takes place in the operation room.

This conclusion is also shared in the 2014 report of the French observatory of medical risks which concludes that $60 \%$ of disputes relate to a surgical procedure. The reason orthopaedics comes to the top of the ranking is mainly because of the number of surgical procedures it carries out, which far exceeds other specialities [13]. In order to protect against a judicial slippery slope leading to an exponential growth in the liability of medical practitioners, medical experts and insurers advise that a relationship of trust-as well as dialogue with the patient-be maintained, even in case of a dispute [1]. Keeping medical files up-to-date in a precise and complete manner is also crucial to ensure protection. The establishment of standardised protocols as well as care recommendations allows for a standardisation of practices. Certain measures, such as the strict application of a security period of rest after a call of duty, obligatory courses on obstetrical manoeuvres and taking specific exams related to gynaecology obstetrics, have led to a decrease in risk events [14].

\section{Conclusion}

The speciality of gynaecologist-obstetrician belongs to a medical branch that is strongly affected by insurance claims in comparison to other specialities. The compensation amount awarded is twice compared to other medical disciplines and can reach sums exceeding one million Swiss francs. This weighs heavily on the total amount of indemnities. Most cases opened by a civil procedure (maximum: 3\% of cases) are resolved amicably through an agreement between the doctor, his/her professional civil liability insurance and the patient, or through a judgement in favour of the doctor based on a legal precept. Certain precautionary measures allow for a decrease in insurance claim costs within current medical practice, such as keeping a complete medical file, maintaining dialogue with the patient in case of disputes, or offering ongoing training in order to prepare medical teams to face the risks inherent to this specialisation. The prevention of legal risks must be integrated into daily practice, the same as any other medical risks $[15,16]$. The risk is to go into a protectionist drift by practicing a defensive medicine [17-19].

\section{References}

1. LM Glaser, Alvi FA, Milad MP (2017) Trends in malpractice claims for obstetrics and gynaecologic procedures, 2005 through 2014. Am J Obstet Gynecol 217(3): 340e1-340e6.

2. Jena AB, Seth Seabury, Darius Lakdawalla, Amitabh Chandra (2011) Malpractice risk according to physician specialty. N Engl Med 365: 629636.

3. Madeleine Hirsig Vouilloz (2017) La responsabilité du médecin, Stämpfli Verlag.

4. (2011) Dupont AS, Dernières tendances de la jurisprudence en matière de responsabilité médicale, in Responsabilité médicale et assurance: 17e Journée de droit de la santé, Olivier Guillod, édit, p. 57.

5. Magali Finon (2015) Le médecin face à la justice, HAL Id: dumas-01132124 Mars 2015, Thèse pour le diplôme d'état de docteur en médecine.

6. Frederiksen LE, Ernst A, Brix N, Braskhøj Lauridsen LL, Roos L, et al. (2018) Risk of Adverse Pregnancy Outcomes at Advanced Maternal Age. Obstet Gynecol 131(3): 457-463

7. Marozio L (2017) Maternal age over 40 years and pregnancy outcome: a hospital-based survey. J Matern Fetal Neonatal Med 32(10): 1602-1608.

8. OmbeletW (2016) Pregnant after assisted reproduction: a risk pregnancy is born! 18-years perinatal outcome results from a population-based registry in Flanders, Belgium. Facts Views Vis Obgyn 8(4): 193-204.

9. (2011) Medical Malpractice Reform. Health cost containment and efficiencies: NCSL briefs for state legislators 71-74.

10. M Gerber, Esther Kraft, Christoph Bosshard (2014) Décision partagée - Médecin et patient décident ensemble. Bulletin des médecins suisses 95: 50.

11. E Bureau, Hermann Mesfen (2014) Les patients contemporains face à la démocratie sanitaire. Anthropologie \& Santé p. 8.

12. R Shojai, Bretelle F, D Ercole C, Boubli L, Piercecchi MD, et al. (2013) Litigation in obstetrics and gynaecology: Experience of a university hospital in France. J Gynecol Obstet Biol Reprod (Paris) 42(1): 71-75.

13. Cichos KH, Ewing MA, Sheppard ED, Fuchs C, Mc Gwin G, et al. (2019) Trends and Risk Factors in Orthopedic Lawsuits: Analysis of a National Legal Database Orthopedics. 42(2): e260-e267.

14. Iverson RE, Heffner LJ (2011) Patient safety series: Obstetrical safety improvement and its reflexion in reserved claims. Am J Obstet Gynecol 205(5): 398-401

15. Cardoso R, Wasifa Zarin, Vera Nincic Sarah, Louise Barber Ahmet, Metin Gulmezoglu, et al. (2017) Evaluative reports on medical malpractice policies in obstetrics: a rapid scoping review, Syst Rev 6(1): 181. 
16. A Prousta, FX Boyer De Latour (2016) Quality is not a problem, it's a solution. Gynécologie Obstetrique \& Fertilité 44 (4): 195.

17. Chervenak FA, Mc Cullough LB (2004) Neglected ethical dimensions of the professional liability crisis. Am J Obstet Gynecol 190(5): 1198-1200.

18. AbdelAziem A, Moawia E Hummeid, Yasir AM Elhassan, Wisal OM Nabag, Mohammed Ahmed A, et al. (2016) Concept of defensive medicine and

\section{ISSN: 2574-1241}

DOI: 10.26717/BJSTR.2019.19.003370

A Feki. Biomed J Sci \& Tech Res

(C) (P) This work is licensed under Creative

Submission Link: https://biomedres.us/submit-manuscript.php litigation among Sudanese doctors working in obstetrics and gynecology. BMC Medical Ethics 17: 12

19. Ortashi O, Jaspal Virdee, Rudaina Hassan, Tomasz Mutrynowski, Fikri Abu Zidan, et al. (2013) The practice of defensive medicine among hospital doctors in the United Kingdom. BMC Med Ethics 14: 42.

\begin{tabular}{|l} 
BIOMEDICAL \\
RESEARCHES
\end{tabular}$\quad$\begin{tabular}{l} 
Assets of Publishing with us \\
\hline -
\end{tabular}

